\title{
Educomunicação: quando pesquisa, extensão e ensino se imbricam!
}

Prof. Dr. Ismar de Oliveira Soares

Professor titular da ECA/USP, supervisor do Curso a distância "Mídias na Educação", do MEC, no Estado de São Paulo, e coordenador da Licenciatura em

Educomunicaşão da ECA/USP.

E-mail: ismarolive@yahoo.com

Resumo: O texto faz um breve resumo do percurso percorrido pela prática de educomunicação, a começar pela pesquisa e extensão cultural, parte das quais destinadas a estudar ações geradas em programas de extensão universitária, passando pelo ensino regular e formal, com a criação dos cursos de graduação e especialização, até a sua difusão com a revista Comunicação \& Educação.

Palavras-chave: Educomunicação; pesquisa; extensão cultural; prática acadêmica; difusão acadêmica.
Abstract: The paper outlines a summary of the journey of educommunication practice, starting with the research and cultural extension, some of them aimed at studying actions developed in university extension programs, passing by regular and formal education, with the undergraduate and specialization courses, and finally, with the Communication \& Education journal.

Keywords: Educommunication; research; cultural extension; academic practice; academic diffuse.

Costuma-se afirmar que a relevância de uma universidade pode ser medida pela articulação que souber promover entre as três áreas constitutivas de sua missão: pesquisa (o avanço do conhecimento mediante a investigação metódica e inédita), ensino regular e formal (a formação profissional dos alunos para atender as demandas por trabalhadores qualificados) e difusão (a socialização do saber junto à sociedade, para criar referenciais para a condução das práticas sociais e laborais).

Em geral, estanques ou fechados em si mesmos, estes três setores da prática acadêmica comportam-se, em alguns casos, como trilhas de um mesmo caminho, ou braços de um mesmo delta que, percorridos ou navegados por um pensamento transdisciplinar, garantem visibilidade, legitimação e reconhecimento a determinadas áreas da prática social.

Foi o que ocorreu com a educomunicação․ Presente no cenário das lutas sociais latino-americanas, ao longo do século XX, a prática ganha identidade no embate entre a pesquisa e a extensão cultural, facilitando e dando coerência à aplicação dos resultados da investigação na solução de problemas

1. Sobre o conceito, ver Ismar de Oliveira Soares. Gestão comunicativa e educação: caminhos da educomunicação. Comunicação \& Educação, São Paulo, Ano VIII, n. 23, p. 16-25, jan./abr. 2002. 
2. Patrícia Horta Alves, em sua tese doutoral intitulada "O Projeto Educom.rádio como política pública" (ECA/USP, 2007), trabalha a relação entre pesquisa e extensão cultural como ação própria do âmbito das políticas públicas.

3. MIIKE, H. S. Oficina de TV, uma proposta educomunicativa: estudo de caso de uma criança abrigada. (Dissertação de Mestrado). Faculdade de Filosofia, Ciências e Letras de Ribeirão Preto da Universidade de São Paulo, 2008. contemporâneos. As intervenções - próprias da extensão - propõem novos problemas que, pesquisados, fazem avançar os conceitos originais, mediante especificações que agregam, modulam e fazem crescer $^{2}$.

Como a fazer girar o ciclo de mútuas interferências, as pesquisas em torno do conceito da educomunicação (parte das quais destinadas a estudar ações geradas em programas de extensão universitária) chegam - 13 anos após a divulgação da pesquisa fundante - ao expressivo número de 97 teses e dissertações. É o que registra o banco de teses da CAPES, no último mês de 2012. Deste total, 41 pesquisas foram produzidas na USP, sendo que 37 delas no Programa de Pós-graduação em Ciências da Comunicação, da ECA/USP.

\section{UM NAMORO COM O EDUCOM!}

Uma das pesquisas desenvolvidas no espaço da USP pertence ao Programa de Pós-graduação em Psicologia da USP, campus de Ribeirão Preto. Trata-se da dissertação de mestrado de Helenita Sommerhalder Miike, defendida em 2008 com o título: "Oficina de TV, uma prática educomunicativa: estudo de caso de uma criança abrigada".

O projeto investigativo buscou compreender que possibilidades de ganhos psicossociais e educativos a realização de práticas educomunicativas poderia trazer para crianças em situação de risco social. Para tanto, tomou como estudo de caso a realidade de uma menina de onze anos que vivia em um abrigo de uma cidade de porte médio, no interior de São Paulo. A pesquisa procurou identificar mudanças na condição de desenvolvimento desta criança, expressas no seu contexto de vida cotidiana, e que poderiam ser consideradas como possivelmente decorrentes da sua participação no projeto.

Miike adotou como suporte teórico-metodológico dois gêneros distintos de referenciais: um primeiro, no âmbito da educomunicação, tendo como referência as conclusões do trabalho do Núcleo de Comunicação e Educação da USP, realizado, entre 1997 e 1999, junto a especialistas em Comunicação/Educação de 12 países da América Latina; um segundo, na perspectiva da psicologia social, fazendo uso dos estudos em torno das redes de significações.

As oficinas de vídeo, oferecidas a um grupo de crianças abrigadas, entre as quais a menina em observação, foram realizadas em 30 encontros, num total de 60 horas, seguindo alguns procedimentos como o "aprender fazendo" e a identificação de conceitos teóricos a partir do contato direto dos participantes com os equipamentos e a linguagem próprios da televisão. $\mathrm{O}$ educador e o técnico do abrigo responsável pelo caso, assim como os professores e a mãe da adolescente, foram ouvidos antes da realização e após a implantação dos instrumentos, visando fazer um levantamento das histórias de vida e uma descrição das crianças nos momentos específicos. 
A descrição inicial da criança em observação foi muito semelhante à existente na literatura sobre a população infantil abrigada, especialmente no que se refere à autoimagem negativa e ao desempenho escolar ruim.

Pois bem, após a participação da menina nas oficinas, o exame de seu retrato presente nos depoimentos dessas pessoas apontou para a existência de efetivas e súbitas mudanças, sempre em sentido positivo. A autora compreendeu que essas diferenças possivelmente foram motivadas pela combinação da maneira com que dialogicamente se estabeleceram interações entre ela e as pessoas com quem conviveu no período do projeto, os papéis atribuídos a ela e a forma como ela os assumiu.

$\mathrm{Na}$ conclusão do trabalho, a autora constatou, ainda, que o projeto permitiu visualizar o uso da linguagem audiovisual (câmera de vídeo) como um dispositivo de desenvolvimento humano capaz de potencializar a experiência de vida das crianças, ao quebrar a relação mítica com o objeto TV e auxiliar a percepção de recursos próprios, especialmente para crianças que ainda não dominam a leitura e a escrita.

A dissertação defendida em Ribeirão Preto revelou o que dezenas de outras, voltadas para a análise dos procedimentos educomunicativos, acabaram confirmando. Referimo-nos a pesquisas realizadas a partir de amostragens distintas, algumas constituídas por pequenos grupos (como, por exemplo, a tese doutoral sobre a ação educomunicativa na prática das ONGs, em diferentes regiões do Brasil, de autoria de Genésio Zeferino Silva Filho, de $2004^{4}$, e outras, abrangendo contingentes maiores de estudantes vinculados a complexas redes de ensino, como a dissertação de Renato Tavares, de 2007, sobre a produção midiática de professores e alunos de 455 escolas de São Paulo ${ }^{5}$ ).

Em todos os casos, revelou-se que a educomunicação traz como vantagem a imediata manifestação da autoestima das pessoas envolvidas, sejam estas profissionais comprometidos com os projetos na área ou mesmo as crianças e jovens em sua busca por um lugar no mundo. Com a autoestima, vêm a disposição para o estudo, a motivação para aprender, o compromisso com a solidariedade, facilmente traduzidos em ações transformadoras, em nível pessoal, grupal, comunitário.

O trabalho de extensão realizado, por exemplo, a partir de 2006, pelo NCE/USP junto à FUNDHAS - Fundação Helio Augusto de Souza, órgão da Prefeitura de São José dos Campos responsável por atender, no contraturno escolar, a um público de 8 mil pessoas, entre crianças e jovens de 8 a 18 anos. Esse trabalho garantiu a criação, na maior cidade do Vale do Paraíba, de um Centro de Referência em Educomunicação e Educação Ambiental que, com autonomia, garante, no presente, a formação continuada de educadores e estudantes não apenas da própria fundação, mas, com o mesmo empenho, de professores e alunos da rede municipal de ensino.

No caso específico da experiência da FUNDHAS, a adesão ao conceito por parte dos beneficiados ficou registrada no "slogan" do banner inteiramente desenhado por seus estudantes, por ocasião do $5^{\circ}$ Encontro de Jovens
4. SILVA FILHO, Genésio Zeferino. Educomunicação e sua metodologia: um estudo a partir de ONGs no Brasil. (Tese de Doutorado). São Paulo, ECA/USP, 2004

5. TAVARES JUNIOR, Renato. Educomunicação e expressão comunicativa: a produção radiofônica de crianças e jovens no projeto educom.rádio. Dissertação de Mestrado. São Paulo, ECA/USP 2007. 
comunicação \& educação • Ano XV|l| • número 1 • jan/jun 2013

Educomunicadores, ocorrido em 2008, com os dizeres: "Um namoro com o Educom". Não há quem desconheça a força da palavra "namoro" no contexto das descobertas que fazem os adolescentes sobre a vida e seus relacionamentos, em busca da construção de suas identidades.

\section{DA ESPECIALIZAÇÃO À GRADUAÇÃO}

Outro dado revelador da imbricação entre pesquisa e extensão cultural no tratamento do tema da educomunicação vem sendo revelado pela produção acadêmica dos alunos dos cursos de especialização da própria ECA/USP. A título de exemplo, o levantamento junto à produção dos trabalhos conclusivos da Especialização em Gestão da Comunicação informa que, entre 1997 e 2010, aproximadamente $20 \%$ dos 500 trabalhos conclusivos voltaram-se para o tema da relação entre comunicação e educação.

Uma segunda experiência de especialização, intitulada "Mídias na educação", oferecida, no território do Estado de São Paulo, desde 2006, pelo NCE/ USP, mediante uma parceria com o MEC e a UFPE, levou à produção de um total de 483 pesquisas voltadas explicitamente para a comunicação e o uso de mídias na prática educativa. (Importante: todas estas pesquisas foram realizadas por professores das redes públicas estaduais e municipais, contando com a orientação de uma equipe de mais de 75 especialistas na área, formados pelo próprio núcleo.)

É surpreendente observar, por outro lado, que a produção de referenciais sobre a educomunicação não tem sido obra exclusiva da academia. $\mathrm{O}$ trabalho de difusão cultural de diferentes centros e organizações não governamentais tem levado o conceito da educomunicação para ambientes que vão além das fronteiras geográficas de suas respectivas atuações. Caso paradigmático foi a produção, por parte da Rede CEP - Comunicação, Educação e Participação, do manual que dá suporte ao macrocampo sobre Comunicação e Uso de Mídias, do programa Mais Educação do MEC, tendo a Educomunicação como referência. O material, elaborado entre em 2007 e 2008, continua disponível, ainda hoje, para mais de 5 mil escolas matriculadas no programa, em todo o país, atendendo a mais de 900 mil alunos.

De seu lado, como é sabido, a Revista Comunicação Ẽ Educação que, com o mesmo empenho, trabalha com a teoria e a prática, ao acompanhar e refletir o que ocorre no Brasil na interface comunicação/educação, vem se apresentando como um dos principais espaços de consolidação dos novos referenciais que nascem das possíveis conexões entre pesquisa e extensão cultural.

Tais fatos, pelas evidências reveladas, levou a Universidade de São Paulo a criar, em novembro de 2009, no espaço do Departamento Comunicações e Artes da ECA, uma licenciatura voltada especificamente ao tema da educomunicação. Completava-se o ciclo de embricamento entre pesquisa, extensão cultural e graduação. 


\section{ARTIGOS NACIONAIS}

A seção de artigos de autores nacionais traz quadro-textos relacionados ao tema dos procedimentos pedagógicos, circunstanciados em ambientes diferentes e para distintos propósitos. O primeiro, de Josias Ricardo Hack, Fernando Ramos e Arnaldo Santos, foca o estudo da linguagem, na busca de uma didática extraescolar possibilitada pelo emprego da metodologia do Digital Storytelling, aplicada como estratégia de aprendizagem no contexto de capacitação corporativa. O segundo, de Carlos Alberto Machado, faz uma leitura de cunho didático-filosófico sobre a literatura vigente, preocupando-se com o vício tecnológico e a desnaturalização da sociedade, testemunhados na ficção científica. Para tanto, faz um estudo sobre a angústia, a felicidade e liberdade no contexto da pós-modernidade, e sobre sua presença nos romances contemporâneos, em que o tema da sobrevivência individual se sobrepõe aos de interesse social. No terceiro artigo, de Waldomiro Vergueiro e Douglas Pigozzi, o assunto é a proficiência no entendimento de mensagens, verificada a partir do estudo dos códigos escritos e visuais possibilitados pelas histórias em quadrinhos. No caso, é analisada a obra Watchmen, do roteirista britânico Alan Moore. Finalmente, Mayra Rodrigues Gomes e Ivan Paganotti voltam-se para a didática do ensino do jornalismo, relatando a experiência de adoção de sítio wiki em sala de aula. Em extensão a essa prática, o artigo apresenta os primeiros passos em direção ao aproveitamento dos trabalhos dos alunos com o intuito de complementar tópicos ou de criar temas relevantes na Wikipédia.

\section{ARTIGOS INTERNACIONAIS}

Os artigos internacionais nos reportam à Espanha e à Colômbia. Têm em comum a preocupação com o sujeito do processo educativo, quer no contexto da sociedade tecnológico-industrial, quer no contexto da sociedade tradicional-indígena. Carlos Busón Buesa, com larga trajetória na UNED - Universidade Nacional de Educação a Distância, de Madri, aborda o problema dos efeitos motivacionais sobre os processos de aprendizagem em torno de conteúdos científicos, exercidos pela maneira como os assuntos dessa natureza são tratados pelo sistema educacional. "Apesar de vivermos em tempos de tecnologias da informação, os alunos contemporâneos mostram uma tendência em se afastar destas questões", afirma o autor, para quem "é preciso adotar novas formas de aprender a aprender."

O segundo texto, de Martha Lucia Izquierdo Barrera, coordenadora da Licenciatura em Etnoeducação e Desenvolvimento Comunitário, da Universidade Tecnólogica de Pereira, na Colômbia, traz para os leitores da revista o paper apresentado durante o IV Encontro Brasileiro de Educomunicação (São Paulo, outubro de 2012), tendo como título "De los paradigmas interculturales a la acción educativa autogestionaria”. O artigo permite ao leitor conhecer uma experiência inovadora de formação de membros de comunidades indígenas por 
comunicação \& educação • Ano XV|l| • número 1 • jan/jun 2013

parte de uma instituição de ensino superior, mediante o emprego dos pressupostos da educomunicação, que é o diálogo intercultural.

\section{GESTÃO DA COMUNICAÇÃO}

Em seu relato de gestão da comunicação em espaço educativo, André Bueno nos traz a experiência do Ponto de Cultura "Centro de Defesa da Criança e Adolescente - CEDECA Interlagos”. O artigo descreve especificamente como são oferecidas as oficinas de fotografia, analisando entrevistas com os participantes, colhidas entre 2007 e 2012. Em sua conclusão, o texto possibilita entender como a fotografia e a Educomunicação podem se associar a projetos voltados para o desenvolvimento humano.

\section{ENTREVISTA}

As recentes pesquisas intituladas, respectivamente, "TIC Educação 2001" (sobre o uso das tecnologias da informação e comunicação nas escolas brasileiras) e "TIC Kids Online Brasil, 2012" (sobre o consumo de internet entre adolescentes de 9 a 16 anos), desenvolvidas pelo Centro de Estudos sobre as Tecnologias da Informação e da Comunicação (CETIC.br), órgão que pertence ao Comitê Gestor da Internet no Brasil (CGI), são objetos da entrevista da presente edição.

Tatiana Jereissati e Juliano Cappi disponibilizam os dados e comentam os resultados, afirmando que a partir deste serviço torna-se mais fácil às autoridades e aos responsáveis pelos processos de educação definir políticas públicas mais adequadas no que diz respeito tanto às oportunidades quantos aos riscos relacionados ao uso da internet em nosso país. Informam também os entrevistados que com esse tipo de coleta e processamento de dados o CGI coloca-se em sintonia com procedimentos semelhantes, em andamento na comunidade europeia.

\section{CRIITICA}

Maria Aparecida Baccega, Fernanda Elouise Budag e Lucas Máximo Ribeiro apresentam um estudo comparado da recepção de dois produtos midiáticos afins, exibidos em dois países latino-americanos: Rebelde (veiculado no Brasil, entre 2006-2007) e Rebeldes (veiculado no México, entre 2011-2012). A intenção do relato é permitir identificar conexões sobre questões relacionadas a consumo presentes nas pautas centrais de ambas as telenovelas, bem como os valores prezados por seus respectivos sujeitos receptores. 


\section{DEPOIMENTO}

A seção traz o depoimento de Janete Souza Oliveira, uma "quase socióloga" que abandonou o curso da Escola Livre de Sociologia e Política para morar na África, onde passou oito anos de sua vida. Janete havia crescido ouvindo dos pais - a doméstica dona Gersina e o motorista Joaquim Adão - histórias do Circo Piolin, instalado, desde 1943, na Praça Marechal Deodoro, na região central da cidade de São Paulo. O depoimento permite ao leitor descobrir a importância do circo e das comédias na vida social das classes menos privilegiadas da pauliceia, nos meados do século XX.

\section{EXPERIÊNCIA}

A presente edição da revista Comunicação $\mathcal{E}$ Educação disponibiliza para o leitor uma experiência que a autora - Maria Isabel Rodrigues Orofino - identifica como pertencente à esfera teórico-metodológica da "mídia-educação". Trata-se da produção e veiculação, no Youtube, de 5 webnovelas realizadas por crianças de classe popular moradoras de uma comunidade na periferia urbana da cidade de São Paulo. Com o relato, que envolve 30 crianças da EMEF Caíra Atayde Alvarenga Midéia, fica demonstrado que a utilização das tecnologias da informação numa perspectiva colaborativa contribui decididamente para mudar o ecossistema comunicativo inerente ao espaço educativo tradicional.

\section{RESENHAS}

A seção destaca três lançamentos próximos ao universo da Educomunicação, a saber: Educomunicação: imagens do professor na mídia, coordenado por Adilson Citelli; Reinventando a educação: diversidade, descolonização e redes, de Muniz Sodré, e, por último, Idade mídia, de Alexandre Sayad. Privilegia também a história da arte cinematográfica, com um comentário sobre o livro de Maria Inês Carlos Magno em torno do filme Meia-noite em Paris, de 2011, abordando o movimento artístico do início do século XX.

Finalmente, a seção apresenta os principais apontamentos do Anuário Obitel 2012, com o texto intitulado "Transnacionalização da ficção televisiva nos países ibero-americanos", num trabalho de coautoria entre Cristina Mungioli e Issaaf Karhawi.

\section{POESIA}

A revista oferece aos seus leitores o texto completo de "O corvo" ("The Raven"), de Edgard Allan Poe. Considerado um dos mais importantes poemas de todos os tempos, nele é representada a misteriosa figura de um corvo, que encarna o inevitável caráter da morte. $\mathrm{O}$ texto, contudo, expande outras área 


$$
\text { comunicação \& educação • Ano XVIII • número 1 • jan/jun } 2013
$$

de significação, promovendo diálogos com a tradição do ultrarromantismo e do sofrimento com a perda da mulher amada. A tradução é do poeta português Fernando Pessoa.

\section{ATIVIDADES EM SALA DE AULA}

Como ocorre em todas as edições, a última parte da revista é dedicada às propostas de tratamento dos temas das revistas nos espaços de sala de aula, mediante o desenvolvimento de projetos pedagógicos. Responde pela seção a educadora e jornalista Ruth Ribas Itacarambi Leão. 